\title{
Terrorism, geopolitics, and oil security: Using remote sensing to estimate oil production of the Islamic State
}

\author{
Quy-Toan Do ${ }^{a}$, Jacob N. Shapiro ${ }^{b}$, Christopher D. Elvidge ${ }^{c}$, Mohamed Abdel-Jelil ${ }^{d}$, Daniel P. \\ Ahn $^{e}$, Kimberly Baugh $^{\dagger}$, Jamie Hansen-Lewis ${ }^{g}$, Mikhail Zhizhin ${ }^{\dagger}$, and Morgan D. Bazilian ${ }^{h,{ }^{*}}$ \\ aResearch Department, The World Bank, United States \\ bolitics Department, Princeton University, United States \\ 'Earth Observation Group, NOAA National Centers for Environmental Information, United States \\ dMiddle East and North Africa Chief Economist's Office, The World Bank, United States \\ eJohns Hopkins University SAIS and Office of the Chief Economist, U.S. Department of State, \\ United States \\ ${ }^{\mathrm{f} C o o p e r a t i v e ~ I n s t i t u t e ~ f o r ~ R e s e a r c h ~ i n ~ t h e ~ E n v i r o n m e n t a l ~ S c i e n c e s, ~ U n i v e r s i t y ~ o f ~ C o l o r a d o, ~ U n i t e d ~}$ \\ States
}

gEconomics Department, Brown University, United States

hPayne Institute, Colorado School of Mines, United States

\section{Abstract}

As the world's most traded commodity, oil production is typically well monitored and analyzed. It also has established links to geopolitics, international relations, and security. Despite this attention, the illicit production, refining, and trade of oil and derivative products occur all over the world and provide significant revenues outside of the oversight and regulation of governments. A prominent manifestation of this phenomenon is how terrorist and insurgent organizations-including the Islamic State group, also known as ISIL/ISIS or Daesh—use oil as a revenue source.

Understanding the spatial and temporal variation in production can help determine the scale of operations, technical capacity, and revenue streams. This information, in turn, can inform both security and reconstruction strategies. To this end, we use satellite multi-spectral imaging and ground-truth pre-war output data to effectively construct a real-time census of oil production in areas controlled by the ISIL terrorist group. More broadly, remotely measuring the activity of extractive industries in conflict-affected areas without reliable administrative data can support a broad range of public policy and decisions and military operations.

\section{Introduction}

While oil resources play a crucial part in conflict, geopolitics, and international affairs [1], the exploitation of oil, like other resources, often occurs where governance is unstable and

\footnotetext{
"Corresponding author. mbazilian@mines.edu.
} 
transparency is absent. Illicit production, refining, and distribution of oil and products occurs even in well-established markets, such as Nigeria [2]. Like other illicit trades, the scale of production is difficult to gauge and daunting for policymakers to ignore [3]. To improve the policy response to conflict in areas with illicit oil production, we adapt earlier methods of measuring oil production from satellite data. We tailor our approach to the setting of the Islamic State group, also known as ISIL/ISIS or Daesh, in Syria and Iraq.

Measuring illicit oil production is important because natural resource extraction substantially affects conflicts. In such areas reliable external measures of forestry, mining, and oil production can enable better approaches to a broad range of challenges. In Colombia and Nigeria, for example, insurgent organizations have long controlled territory where oil is produced, and in many regions around the world public and reliable field-level production numbers are difficult to find. Estimating production remotely can enable governments and international organizations to identify illegal or untaxed production and to better understand its role in post-conflict economies as well as the impact of sanctions, trade restrictions, and other policy interventions.

Previous work on the relationship between resource exploitation and conflict underscores the relevance of this study. Even though a main concern is that resource wealth can fund armed groups either directly or via taxation, variation in the relationship occurs. For instance, Sánchez de la Sierra [4] finds that positive prices shocks to a bulky commodity leads armed groups to create a monopoly of violence to impose taxation and regulate production in Eastern Congo. Along the same lines, Maystadt et al. [5] use data on international mineral prices and historical mining concessions to show that armed groups tend to reduce violence in areas near the mines when prices go up. This "protection effect" is consistent with violence reducing economic profitability. Others find that fighting around diamond mines did not affect civilians in Sierra Leone, but was rather limited to violence among soldiers [6,7]. This result is echoed in Ziemke [8], who finds that violence against civilians was lower in diamond areas of Angola. Finally, Dube and Vargas [9] find that price shocks have heterogeneous effects: in labor-intensive sectors, commodity price drops result in higher incentives to join armed groups, while in the capital-intensive sector the rise in the price elicits predatory behavior from armed groups.

This study also relates to previous work on the relationship between conflict and oil extraction in particular Colgan [10] considers the impacts of conflict and the oil sector primarily as it influences domestic policy formation. Relatedly, Månsson [11] develops a framework to consider the wider issues of energy and conflict. Further work on conflict and offshore oil [12], how these issues relate to renewable energy and concepts of energy independence [13,14], and how these issues manifest in Russian and the Ukraine [15] all appear in ERSS.

This paper combines the focus on oil and conflict with the emerging literature that uses remote sensing to measure oil production. Our approach builds on previous work establishing globally how flared gas volumes from oil fields and refineries can be measured with nighttime light detecting sensors such as DMSP-OLS and SNPP-VIIIRS [16,17].

Remote sensing based estimates of gas flaring have been validated at the production site [18]

Energy Res Soc Sci. Author manuscript; available in PMC 2019 October 01. 
and country-year levels [19] and found to be accurate and unbiased. Additional work uses satellite observations to examine the behavior in extractive industries in low-governance regions $[20,21]$.

We make several contributions to the literature. In the remote sensing literature, we use a new method combining visible and infrared bands to detect low level production with greater sensitivity. While previous methods failed to distinguish low intensity flares from other signals of conflict in our setting, our algorithm to detect and calibrate flaring with light of the visible band when the infrared signal is below noise level is novel and effective. Further, while earlier studies have documented a robust positive correlation between radiant heat as measured from satellite and flared gas volume at the production site, we quantitatively estimate a structural relationship between oil production and radiant heat, then use the estimates to predict production in places where radiant heat can be measured but production cannot. This is, to our knowledge, the first attempt to do so. In the oil and conflict literature, we demonstrate that using remote sensing can be an appropriate method to measure socio-economic activity in environment where direct observation is either infeasible or prohibitively expensive. Variants on the approach presented here could be applied in a much broader set of geographies and circumstances.

Section 2 considers the context of Islamic State oil production. Section 3 presents our methodology, Section 4 provides results, and Section 5 concludes.

\section{Background on Islamic State oil production}

The non-state insurgent organization known as the Islamic State group (also called the Islamic State [IS], the Islamic State of Iraq and the Levant [ISIL], the Islamic State of Iraq and al-Sham [ISIS], or Daesh, its Arabic acronym) took control of large swathes of territory in Syria and Iraq beginning in mid-2013 (Fig. 1). ${ }^{1}$ Its rapid territorial expansion began when fighters from the Islamic State of Iraq (ISI) started operating in Syria in April 2013 and accelerated from early 2014 onwards when the group moved aggressively back into Iraq [22]. For a time, the group was considered the richest jihadist group in the world and was thought to raise money from a variety of sources [23]. In 2014 and 2015 revenue from oil production in areas the group controlled was often cited as its largest potential source of revenue flow, with estimates of weekly oil revenue ranging from "several million" to US $\$ 28$ million $[24,25]$. Any reasonable assessment of the organization's long-run survival prospects had to account for these revenues and identify how sustainable they were [26]. Yet no reliable sources existed at the time. Beginning in late of 2015, ISIL steadily lost territory in both Iraq and Syria, but still maintained substantial territory in both countries as of early 2017.

Much was written in the media about the ISIL oil revenue stream, including its severe decline due to Coalition operations [27-49]. ${ }^{2}$ Warrick [50] shows how satellite images can identify ISIL micro-refining (or "teapot") capability, asserting that " $[t]$ he proliferation of

\footnotetext{
${ }^{1}$ We henceforth use ISIL, Daesh, and Islamic State interchangeably.

${ }^{2}$ For more recent coverage see, e.g., https://www.brookings.edu/on-the-record/how-isis-uses-oil-to-fund-terror/ or https:// www.newyorker.com/news/news-desk/the-isis-oil-trade-from-the-ground-up.
} 
micro-refineries is the latest sign of strain in the group's self-declared caliphate, which has lost half its territorial holdings in Iraq since late 2014." Robinson et al. [51] offer a wider look at how remote sensing techniques can be employed to understand the ISIL economy. Several news reports, show the more recent strategy by the Trump Administration against ISIL oil [52]. Metrics of the effort include the amount of oil trucks across the supply chain from distribution to production and refining destroyed by Coalition forces. The numbers show a massive uptick in targets just in the first half of 2017, part of the roughly two year old Operation Tidal Wave II. Significant detail on the ways the failing ISIL is finding revenue are detailed in a recent article in the Financial Times, which includes starting their own currency [53].

Early accounts of the group's oil production and the revenues generated indicated that oil was a significant source of financing for the organization. The 2014 Oil Market Report of the International Energy Agency estimates an output of 70,000 barrels per day (bpd) [54]. Other news outlets give numbers around 50-60,000 bpd yielding an income of US $\$ 2.5 \mathrm{~m}$ per day [55] to more than US\$3m per day [56]. Early estimates by the US Departments of State and Treasury put the organization's oil revenues at around US $\$ 1 \mathrm{~m}$ per day [57]. These estimates were then revised down to "a couple million dollars a week" after the U.S. started air-strikes against the organization's assets [58]. Views as to whether ISIL was financing itself through oil, external support, extortion, or taxes then evolved, with higher emphasis put on taxes and extortion as primary sources of revenues over time. Die Zeit for instance reported December 2014 oil revenues to be a mere US $\$ 370,000$ per day or even lower at US $\$ 260,000$ [59]. An October 2015 article however gives an estimated output of 34-40,000 bpd, earning the organization an average of US $\$ 1.5 \mathrm{~m}$ per day [60]. In sum, there was no consensus on the production numbers or revenue they created.

\section{Methodology}

\subsection{Data}

We use data from the Visible Infrared Imaging Radiometer Suite (VIIRS) sensors deployed on the NOAA/NASA Suomi NPP satellite $[17,61,62]$ to detect location of all oil flares over Syria and Iraq from March 2012 to November 2016. VIIRS data have moderate spatial resolution ( $\sim 1 \mathrm{sq} \mathrm{km})$ and cover the globe every $24 \mathrm{~h}$. We used a combination of manual infrastructure checks and algorithms to ensure all flaring sites were associated with oil production [63]. For each oil production site in the region we use news outlets' reports, agencies' press releases and Institute for the Study of War (ISW) maps allow us to assign individual oil wells to the Islamic State group's control at the daily level. During our period of study, 42 production sites in both Syria and Iraq (34 in Syria and 8 in Iraq; see map on Fig. 1) had been or are under ISIL control, out of a total of 75 identified oil sites in Syria and 114 in Iraq. Finally, we combine the satellite data with data on oil production at ISIL and nearby oil fields obtained from IHS Energy Intelligence and Wood Mackenzie Refs. [6466]. Production data included field name, location, and annual oil production in barrels per day from 2012 to 2015 for 22 significant oil fields in Syria and Iraq comparable to those under ISIL control. 


\subsection{Calibration}

Our approach relies on the property that the extraction of oil is associated with the liberation of natural gas, primarily methane, which is initially dissolved in crude oil in constant proportions. In the region of study, the default mode of operation is to flare this gas, hence generating radiation that is captured by VIIRS sensors. To determine the proportion of oil to gas flared (RH), we estimated the relationship between the log of annual mean RH and log of annual mean barrels oil produced per day from the production data of 48 field-year observations. Consistent with previous work [16,17], we found a robust relationship between radiant heat and oil output that closely approximated previous estimates with modest and unbiased noise. Provided the oil-RH relationship estimated using data prior to the seizure of oil fields by ISIL still holds thereafter, we can make consistent statistical inference about contemporaneous volume of crude oil extracted from contemporaneous measures of RH.

\subsection{Venting}

Oil extraction can take place without gas flaring, a process called venting. Although there was no evidence of venting the sample of study, we assign historic output values in cases without a sensor detection to account for this possibility. At any given moment, a site is in one of three production states:

S1: The site is producing with natural gas flaring. Oil production with gas flares is the standard production technique in the sample. No regulatory impediments curtailed gas flaring in Syria and Iraq before the oil fields were contested [67].

S2: The site is producing without gas flaring (i.e., venting). A site that extracts crude oil could simply vent the accumulated natural gas. Venting would happen on a site if: (i) the operator voluntarily shuts down the pilot flame in the flare stack; or (ii) long periods of inactivity extinguish the pilot, which is not re-ignited as production resumes.

S3: The site is inactive. A site might become inactive if fighting has damaged productive infrastructure or no qualified personnel are available to operate the site.

Distinguishing between these production states is important since the lack of radiant heat (RH) does not imply an absence of oil production: venting remains a possibility. Because the narrow spectral bands used in the estimation of RH-the near-infrared (NIR) bands M7 and M8, the short-wave-infrared (SWIR) band M10, and the mid-wave-infrared (MWI) bands M12 and M13-are not sensitive enough to detect low light from low-intensity flaring, we also make use of data from VIIRS' Day/Night band (DNB). DNB is a wide, visible, and NIR imaging spectral band designed to detect moonlit clouds. The DNB's low detection limits make it possible to detect electric lighting present at the Earth's surface which cannot be sensed in the infrared spectral channels [68-71]. DNB is even sensitive to moonlight reflection on the Earth. DNB detection, once the effect of the lunar cycle has been accounted for [62], therefore allows discriminating between states S2 and S3 when no infrared signals are detected.

Fig. 2 illustrates how the RH, temperature, and DNB trends correspond to production states and major events at Ajil oil field in Iraq. From 2012 through 2013, consistently high RH (top 
panel) and temperature (middle panel) indicate production activity was normal (S1). When ISIL takes over in June 2014 through January 2015, flaring intensity drops substantially and temperature detections become sporadic; yet, DNB measures (bottom panel) remain substantial and are mostly greater than would be possible with electrical lighting. This pattern indicates a mix of activity with flare (S1) and activity without flare (S2). Consistent with this interpretation, an engineer at the site told Reuters in July 2014 that ISIL fighters were pumping low volumes of oil from the field [72]. Finally, from January to March 2015 there is no activity at the site (S3) since only the lunar cycle lighting is detected (bottom row). After March 2015, we observe fires from fighting as ISIL flee the site and a period of low-level DNB radiance before regular activity resumes.

\subsection{Validation}

As a validation exercise, we compare our estimates with the best available intelligence of ISIL oil production [73]. On 15 May 2015, U.S. Army Special Forces killed a senior ISIL leader known as Abu Sayyaf, also known as Fathi al-Tunisi, the alleged head of the ISIL oil company. According to the U.S. Department of Defense, Abu Sayyaf, "helped direct the terrorist organization's illicit oil, gas and financial operations." This raid yielded significant amounts of intelligence on the ISIL economy, including administrative data providing ISIL oil production at the governorate-month level for September 2014-January 2015. We aggregate to monthly totals to avoid error in interpreting administrative divisions.

\section{Results}

Fig. 3 reports our production estimates with 95\% confidence intervals from January 2014 through November 2016. We find ISIL oil production peaked at roughly 86,000 barrels per day (bpd) in late July 2014 and declined steadily thereafter, averaging approximately 56,000 bpd in the second half of 2014. Production dropped through most of 2015 until rising briefly in late 2015 to $52,000 \mathrm{bpd}$. In these figures, we assume that fields without a radiant heat signal could be venting when the DNB detection is above the lunar illumination threshold (S2) and assign historical production on venting days. The estimates are slightly lower without this substitution [63]. The confidence intervals account for uncertainty in the calibration of radiant heat to barrels of oil. As a benchmark, major oil producing countries produce on the scale of 500,000 (Ecuador) to 10,000,000 bpd (Saudi Arabia). We reject the conclusion that ISIL production at its peak was comparable to a major petrostate given the upper bound of the confidence interval.

Several precautions ensure these estimates provide an upper bound on ISIL oil production. First, as the gas-to-oil ratio (GOR) gradually increases as oil is extracted, our inferences based on the assumption that the GOR remained constant at its pre-war level will overestimate output when converting RH to oil production. Second, our assumptions are intentionally biased towards over-estimating rather than under-estimating production. For example, the cutoff value we choose to separate electric lights from low-intensity flaring is set at a level that rules out electric lights with probability one, while infrared detection still happens at much lower levels of radiance. Last, we assign cloudy days the average of production at the site over the month. This method is generous since production is highly 
sporadic at some sites and even one day of production will be smoothed over the entire month. We performed a validation of this procedure where we randomly assigned clouds to $10 \%$ of the observations and obtained higher estimates.

Our findings, while lower than some accounts provided in the media, are consistent with estimates for the early period of ISIL control that relied on captured documents [73]. In particular, administrative data captured from the Abu Sayyaf raid posits daily production ranging from 52,120 bpd to 55,560 bpd in the time frame from roughly June to October 2014. These numbers are well within the bounds of our $95 \%$ confidence intervals and very close to our point estimates (Fig. 4). Despite the consistency, other figures available in the documents seized during the Abu Sayyaf raid suggest potential problems with ISIL's administrative data. For example, the captured documents indicate significant output for the At Tayyanah field in the Al Khayr Governorate, for which satellite data detected no visual activity and which was understood to be non-active prior to ISIL takeover. Likewise, simple arithmetic inconsistencies reduce confidence in the accuracy of these records. It is also plausible that internal political motivations that may bias administrative data upwards. Overall, even if the Abu Sayyaf records contain some inaccuracies, they still provide a rough signal of the level of production that our results meaningfully replicate.

The decline in oil production occurred as a result of both closing oil fields and lowered production at active oil fields. In total, we observe no activity during ISIL control for $68.5 \%$ of field-days and regular activity during ISIL control for $9.9 \%$ of field-days. This degree of low activity and no activity during ISIL control is irregular in comparison to the historical activity of the fields before ISIL took control. Fig. 5 displays the portion of sites observed with a flare (column 1), the mean RH at all sites (column 2), and the mean RH at active sites (column 3), a rough measure of production intensity, for ISIL and nearby non-ISIL oil fields over time. All measures are normalized with pre-war values (March - June 2012) in row 2 to highlight changes over time. We observe that fields ISIL would control at some time after June 2014 had substantially reduced flaring activity by mid-2013 both in terms of the share of days flaring and average radiant heat per active flare. We also observe additional reductions in flaring activity in late 2015. We interpret these patterns as indication that ISIL was unable to operate many wells they came to control. Since many fields were contested for years of war prior to ISIL control, it is highly plausible that the infrastructure was destroyed or improperly maintained prior to their arrival. A potential lack of personnel with the right skills could have compounded the difficulty of rebuilding and operating the sites. Territory losses in 2016 further contributed to the production fall.

\section{Conclusions}

With satellite data, we estimate oil production in territory under ISIL's control. Our results show that ISIL performed poorly in comparison to historical trends at extracting oil in the fields under its control. There are no reliable price data on which to gauge how this modest production quantity translated into income. Early reports, however, recount that ISIL was selling at a discounted price, ranging from $\$ 20$ to $\$ 35$ dollars in 2014 [74], while a subsequent report indicated that prices depend on the field of origin, and that some fields charged $\$ 40$ to $\$ 45$ dollars per barrel [75]. At such levels, even assuming no investments in

Energy Res Soc Sci. Author manuscript; available in PMC 2019 October 01. 
maintenance, the annual revenue from oil would be far below many published estimates.

Assuming a $\$ 30$ per barrel average price and no investments in maintenance, net oil revenues in 2015 would have been roughly $\$ 380 \mathrm{M}$, well short of the funds needed to compete on the battlefield against the combined forces arrayed against the group in that year. Moreover, the significant global oil price fall from 2014 to 2016 exacerbated the revenue fall when production declined in 2015 and 2016.

One reason why our estimates differ from many publicly-available ones is small sample size. To our knowledge, prior estimates relied on what is effectively a survey of ISIL's oil assets. Information was obtained from a few selected sites and at specific dates on the basis of key documents or interviewee self-reports, which were then extrapolated. In spite of being supplemented with expert opinions, generalizations to the universe of ISIL-controlled oil facilities are intrinsically imprecise in that the underlying data have observations that are few and might not be representative, therefore leading to imprecise and potentially biased inferences. Updating these estimates over time faces similar methodological challenges. The approach proposed here instead conducts a real-time census of ISIL oil production facilities with daily temporal resolution. The estimates coming from our analysis are not inferences made from observations on a few selected sites and at a few selected dates but from all sites and in real time. Thus, they have the substantial advantage of enabling less bias than previous estimates of the impact of various kinds of events (e.g., attacks, leadership conflicts, territorial losses, etc.) on oil production.

Our approach adds accuracy and transparency to the measurement of economic activity in poorly governed and conflict afflicted territories that is needed to improve the policy response. Reliable external measures of oil output in conflict afflicted settings can enable better approaches to a broad range of policy and military challenges. In this case, the main military response was Operation Tidal Wave II, based on Operation Tidal Wave 1, which targeted Nazi oil supplies in Romania during World War II. According to the US Department of Defense, the operation aims to "...target ISIL's entire oil distribution chain, which includes trucks, wellheads, pumps and collection points" in part because oil funded an estimated 50\% of ISIL operations [76]. Location-date level production developed with our method can ensure this policy response is accurate, timely, and targeted. More broadly, the approach can be adapted to inform planning for short-term humanitarian assistance and long-term reconstruction. Even though oil production is a major source of revenue, among the world's poorly-governed states, few report reliable oil production numbers. In these settings, our method of measuring production can provide critical inputs for governments and international organizations to establish sound economic policy, identify illegal or untaxed production, and assess the impact of policy changes.

\section{Acknowledgments}

The authors are grateful to Jishnu Das, Shanta Devarajan, Fabrice Mosneron Dupin, Tarek Ghani, Guy Grossman, Martyn Howells, and Roy van der Weide for helpful comments. The views and opinions expressed are those of the authors and do not necessarily represent the views or official positions or policy of the U.S. Department of State, U.S. National Oceanic and Atmospheric Administration, the U.S. Department of Commerce, the U.S. Government, or the World Bank, its Board of Executive Directors, or the governments they represent. The institutions do not guarantee the accuracy of the data included in this work. The boundaries, colors, denominations, and other information shown on any map in this work do not imply any judgment on the part of the institutions above 
concerning the legal status of any territory or the endorsement or acceptance of such boundaries. This paper is based on a World Bank Policy Working Paper [63], and funded by Empirical Studies of Conflict Project (ESOC) and the Development Research Group of the World Bank.

\section{References}

1. Yergin D. The Prize. Simon and Schuster; 1990.

2. Hoffman L, Melly P. Nigeria’s Booming Borders. Chatham House; UK: 2015.

3. OECD. Terrorism, Corruption, and the Criminal Exploitation of Natural Resources. Paris: 2017.

4. de la Sierra Raúl Sánchez. On the origins of the state: stationary bandits and taxation in Eastern Congo. University of California Berkeley; 2017. Working Paper

5. Maystadt Jean-FrancoisDe Luca GiacomoSekeris Petros G, Ulimwengu John. Mineral resources and conflicts in DRC: a case of ecological fallacy? Oxford Economic Papers. 2014

6. Bellows JohnMiguel Edward. War and local collective action in Sierra Leone. J Public Econ. 2009; 93(11):1144-1157.

7. Humphreys MacartanWeinstein Jeremy M. Handling and manhandling civilians in civil war. Am Polit Sci Rev. 2006; 100(3):429.

8. Ziemke Jennifer J. From Battles to Massacres. ProQuest. 2008

9. Dube OeindrilaVargas Juan F. Commodity price shocks and civil conflict: evidence from Colombia. Rev Econ Stud. 2013; 80(4):1384-1421.

10. Colgan Jeff D. Oil, domestic politics, and international conflict; Energy Res Soc Sci. Mar 1, 2014 198-205. http://dx.doi.org/10.1016/j.erss.2014.03.005

11. Månsson A. Energy, conflict and war: towards a conceptual framework; Energy Res Soc Sci. Dec 4, 2014 106-116. http://dx.doi.org/10.1016/j.erss.2014.10.004

12. Nyman Elizabeth. Offshore oil development and maritime conflict in the 20th century: a statistical analysis of international trends; Energy Res Soc Sci. Mar 6, 2015 1-7. http://dx.doi.org/10.1016/ j.erss.2014.10.006

13. Månsson André. A resource curse for renewables? Conflict and cooperation in the renewable energy sector; Energy Res Soc Sci. Nov 10, 2015 1-9. http://dx.doi.org/10.1016/j.erss.2015.06.008

14. Nance Mark T, Boettcher William A, III. Conflict, cooperation, and change in the politics of energy interdependence: an introduction; Energy Res Soc Sci. Feb 24, 2017 1-5. http://dx.doi.org/ $10.1016 / j$.erss.2016.12.020

15. Van de Graaf ThijsColgan Jeff D. Russian gas games or well-oiled conflict? Energy security and the 2014 Ukraine crisis; Energy Res Soc Sci. Feb 24, 2017 59-64. http://dx.doi.org/10.1016/j.erss. 2016.12.018

16. Elvidge Christopher D, Ziskinl DanieBaugh Kimberly E, Tuttle Benjamin T, Ghosh TilottamaPack Dee W, Erwin Edward H, Zhizhin Mikhail. A fifteen year record of global natural gas flaring derived from satellite data. Energies. 2009; 2(3):595-622.http://dx.doi.org/10.3390/en20300595

17. Elvidge Christopher D, Zhizhin MikhailBaugh KimberlyHsu Feng-ChiGhosh Tilottama. Methods for global survey of natural gas flaring from visible infrared imaging radiometer suite data. Energies. 2015; 9(1):14.

18. Zhang XiaodongScheving BeauShoghli BaharehZygarlicke ChrisWocken Chad. Quantifying gas flaring CH4 consumption using VIIRS. Remote Sens. 2015; 7(8):9529-9541.http://dx.doi.org/ $10.3390 /$ rs 70809529

19. Elvidge Christopher D, Zhizhin MikhailBaugh KimberlyHsu Feng-ChiGhosh Tilottama. Global survey of 2012 natural gas flaring from VIIRS data. Energies. 2015; 8

20. LaJeunesse Connette Katherine J, Connette GrantBernd AsjaPhyo PaingAung Kyaw HtetTun Ye LinThein Zaw MinHorning NedLeimgruber PeterSonger Melissa. Assessment of mining extent and expansion in Myanmar based on freely-available satellite imagery. Remote Sens. 2016; 8(11)

21. Saavedra SantiagoRomero Mauricio. Local incentives and national tax evasion: the response of illegal mining to a tax reform in Colombia. Stanford University; 2017. Technical Report

22. Johnston Patrick B, Shapiro Jacob N, Shatz Howard J, Bahney BenjaminJung Danielle F, Ryan PatrickWallace Jonathan. Foundations of the Islamic State: Management, Money, and Terror in Iraq, 2005-2010. RAND Corporation; Santa Monica, CA: 2016. 
23. FATF. Financing of the Terrorist Organisation Islamic State in Iraq and the Levant (ISIL). 2015

24. Brisard Jean-CharlesMartinez Damien. Islamic state: the economy-based terrorist funding. Thomson Reuters Accelus; 2014 Oct. Technical Report

25. Cohen David S. Prepared Testimony of Under-Secretary Cohen Before the House Financial Services Committee on the Islamic State and Terrorist Financing. 2014

26. Hansen-Lewis JamieShapiro Jacob N. Understanding the Daesh economy. Perspect Terror. 2015; 9(4)

27. Ahram, Al Qaeda. Leaves East Syria Strongholds to Islamic State: Monitor. 2014 Jul 3.

28. Al Arabiya. Isis Militants Seize Another Oil Field in Syria's Deir el-Zour. 2014 Jul 4.

29. Alhadath news. Daesh Retreats from al Thayem Oil Field. 2015 Jan 15. translated from Arabic.

30. Aljazeera. Syria's Oil Finances Daesh. 2014 Sep 18. translated from Arabic.

31. Aljazeera. Iraqi Forces near Gayarrah. 2016 Jun 23. translated from Arabic.

32. Aljazeera. Fire in Ajil Field. 2015 Mar 5. translated from Arabic.

33. Aljomhuria. Why Daesh Is Aiming to Control Oil and Gas Fields in Syria. 2014 Jul 18. translated from Arabic.

34. Asharq Alarabi. Who Controls Syria's Oil?. 2014 Sep 22. translated from Arabic.

35. Asharq Awsat. 60 Percent of Syria's Oil in the Hands of Daesh. 2014 Jul 11. translated from Arabic.

36. CNN Group. Isis Takes Major Syrian Oil Field. 2014 Jul 3.

37. Deutsche Welle. Daesh Fighters Control the Entire Raqqa Governorate. 2014 Aug 24. translated from Arabic.

38. El Fagr. Fire in Qayarrah Under Control. 2016 Dec 24. translated from Arabic.

39. Eqtsad. Daesh Controls al Kharrata Oil Field. 2014 Jun 6. translated from Arabic.

40. International Business Times. Isis Smuggling US\$50m of Oil Monthly to Fund Medieval Caliphate in Iraq and Syria. 2014 Jul 23.

41. Reuters. Militants Attack Iraqi Air Base. Overrun Oil Site. 2014 Jun 25.

42. Reuters. Isis Burns Oil Field East of Tikrit in Defensive Maneuver, Witness Says. 2015 Mar 5.

43. Revolutionary Forces of Syria Media Office. Coalition Planes Target al Omar. 2015 Nov 13. [Translated from Arabic].

44. Russia Today. Daesh Burns Wells in Gayarrah. 2016 Jul 10. translated from Arabic.

45. Syrian Daesh Controls 90 Percent of Deir Ezzour Governorate in Eastern Syria, (2014) [translated from Arabic], 14 July

46. Syriahr. Airstrikes on al Omar Field. 2015 Nov 4. translated from Arabic.

47. The Irish Times. More US Air Attacks on Islamic State Oil Fields Planned. 2015 Oct 28.

48. The New York Times. U S Steps up its Attacks on ISIS-Controlled Oil Fields in Syria. 2015 Nov 12.

49. U S Department of Defense. Iraq and Syria: Isil's Reduced Operating Areas as of April 2015. 2015

50. Warrick J. Satellite Photos Show Islamic State Installing Hundreds of Makeshift Oil Refineries to Offset Losses from Airstrikes. Washington Post. 2016

51. Robinson EricEgel DanielJohnston Patrick B, Mann SeanRothenberg Alexander D. When the Islamic State Comes to Town: The Economic Impact of Islamic State Governance in Iraq and Syria. RAND Corporation; Santa Monica, CA: 2017.

52. Reed M. Blowing up the Islamic State's Oil Company Foreign Policy USA. 2016

53. Financial Times. ISIS Finds Escape Route for the Profits of War. London, UK: 2017.

54. International Energy Agency. Oil market report, Technical Report. 2014 Oct.

55. Giovanni Janine DiGoodman Leah McgrathSharkov Damien. Newsweek. How does ISIS Fund its Reign of Terror?. 2014 Nov 6.

56. Associated Press. Islamic State Group's War Chest is Growing Daily. 2014 Sep 15.

57. Treasury. Remarks of Under-Secretary for Terrorism and Financial Intelligence. In: Cohen David S, editorCarnegie Endowment for International Peace, Attacking ISIL's Financial Foundation. 2014. 
58. Bloomberg View. Cutting Islamic State's Purse Strings. 2015 Jan 6.

59. Die Zeit. The Business of the Caliph. 2014 Dec 4.

60. Financial Times. ISIS inc: How Oil Fuels the Jihadi Terrorists. 2015 Oct 14.

61. Elvidge Christopher D, Zhizhin MikhailBaugh KimberlyHsu Feng-Chi. Automatic boat identification system for VIIRS low-light imaging data. Remote Sens. 2015; 7(3):3020-3036.

62. Elvidge Christopher D, Zhizhin MikhailHsu Feng-ChiBaugh Kimberly E. VIIRS Nightfire: satellite pyrometry at night. Remote Sens. 2013; 5(9):4423-4449.

63. Do Quy-ToanShapiro Jacob N, Elvidge Christopher D, Abdel-Jelil MohamedAhn Daniel P, Baugh KimberlyHansen-Lewis JamieZhizhin Mikhail. How much oil is the Islamic State Group producing?: Evidence from remote sensing. World Bank; Washington, DC: 2017. Policy Research Working Paper No. 8231

64. IHS Energy Intelligence. Global Exploration \& Production Service. Field Reports for Iraq and Syria. 2015Field Reports, IHS Energy Intelligence

65. Wood Mackenzie. Syria Upstream Summary. 2014 Dec.Country Report, Wood Mackenzie

66. Wood Mackenzie. Iraq Upstream Summary. 2015 Dec.Country Report, Wood Mackenzie

67. World Bank. Regulation of associated gas flaring and venting: a global overview and lessons. World Bank Group; 2010 Jul. Working Paper 29554

68. Jing XinShao XiCao ChangyongFu Xiaodong Yan Lei. Comparison between the Suomi-NPP daynight band and DMSP-OLS for correlating socio-economic variables at the provincial level in China. Remote Sens. 2015; 8(1):17.

69. Li XiXu HuiminChen XiaolingLi Chang. Potential of NPP-VIIRS nighttime light imagery for modeling the regional economy of China. Remote Sens. 2013; 5(6):3057.

70. Shi KaifangHuang ChangYu Bailang Yin BingHuang YixiuWu Jianping. Evaluation of NPP-VIIRS night-time light composite data for extracting built-up urban areas. Remote Sens Lett. 2014; 5(4): 358-366.

71. Zhou YukeMa TingZhou ChenghuXu Tao. Nighttime light derived assessment of regional inequality of socioeconomic development in China. Remote Sens. 2015; 7(2):1242.

72. Hameed SaifEvans Dominic. Islamic State Torches Oil Field near Tikrit as Militia Advance. 2015 Mar 5.

73. Sayyaf AbuState Islamic. Diwan of Natural Resources, Oil and Gas Division-Oil and Gas Report 003 \#82. 2015 Seized May 15, 2015 from Abu Sayyaf, Declassified 2017.

74. Financial Times. Inside ISIS inc: The Journey of a Barrel of Oil. 2016 Feb 29.

75. Shelley Louise. Blood Money, Foreign Affairs. 2014

76. Ferdinando L. Coalition Cripples ISIL Oil Distribution. Department of Defense. 2016

Energy Res Soc Sci. Author manuscript; available in PMC 2019 October 01. 


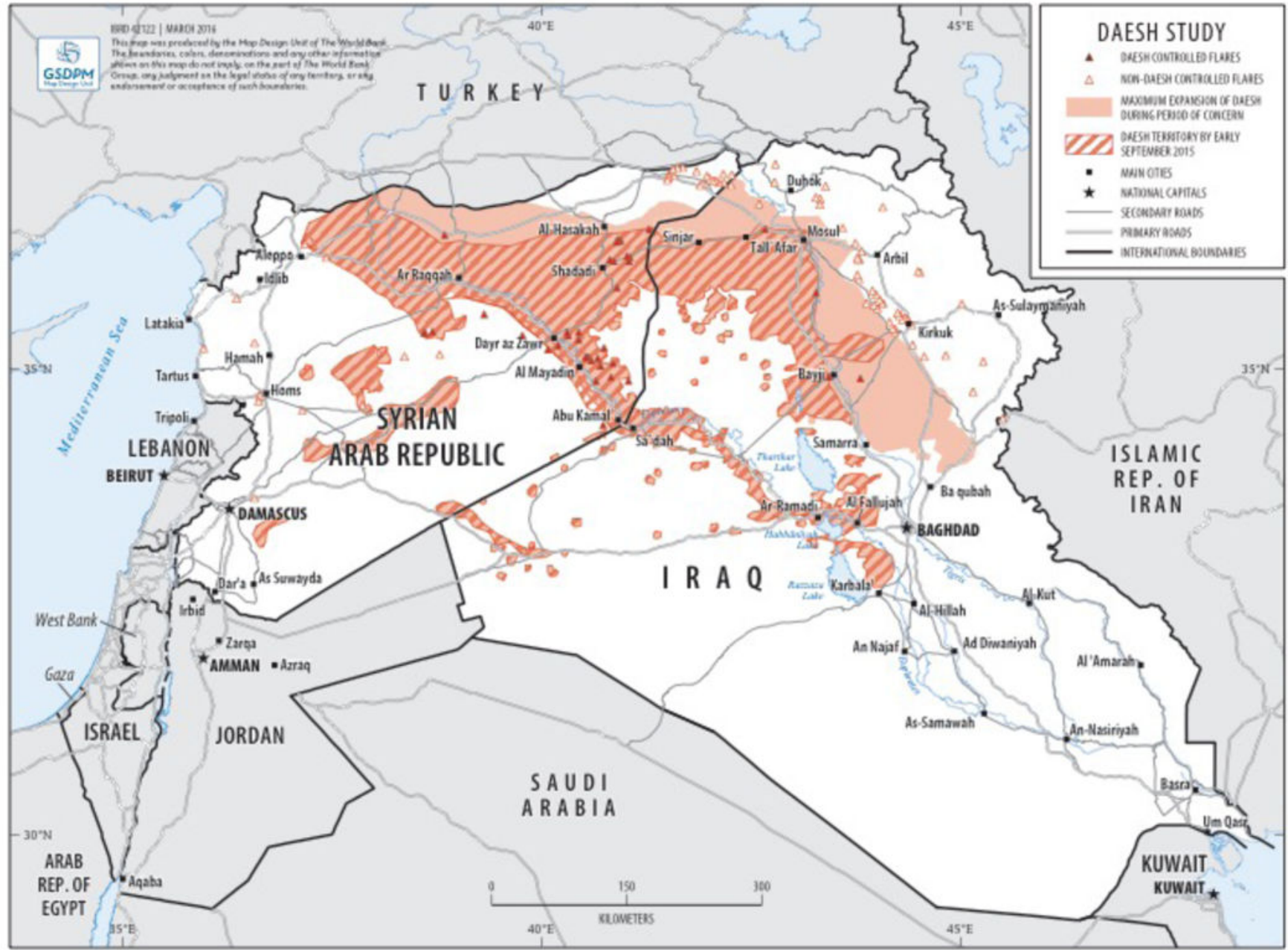

Fig. 1.

Iraq and Syria oil production, fields, and ISIL control, March 2016.

Energy Res Soc Sci. Author manuscript; available in PMC 2019 October 01. 


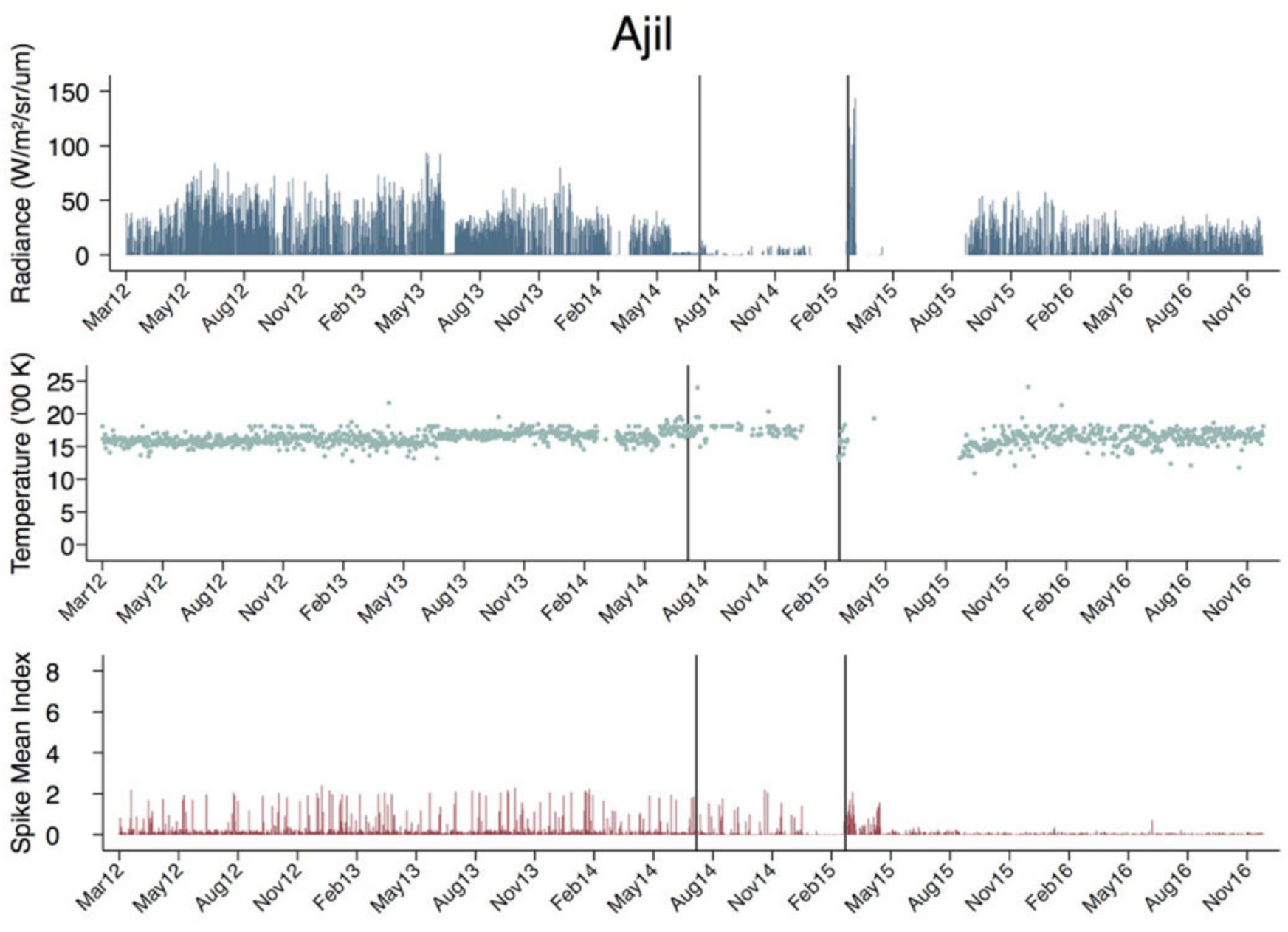

Fig. 2.

Radiance, temperature, and day night band (Spike Mean Index) at Ajil oil field May 2012 to

November 2016. Black lines delineate period of ISIL control. 


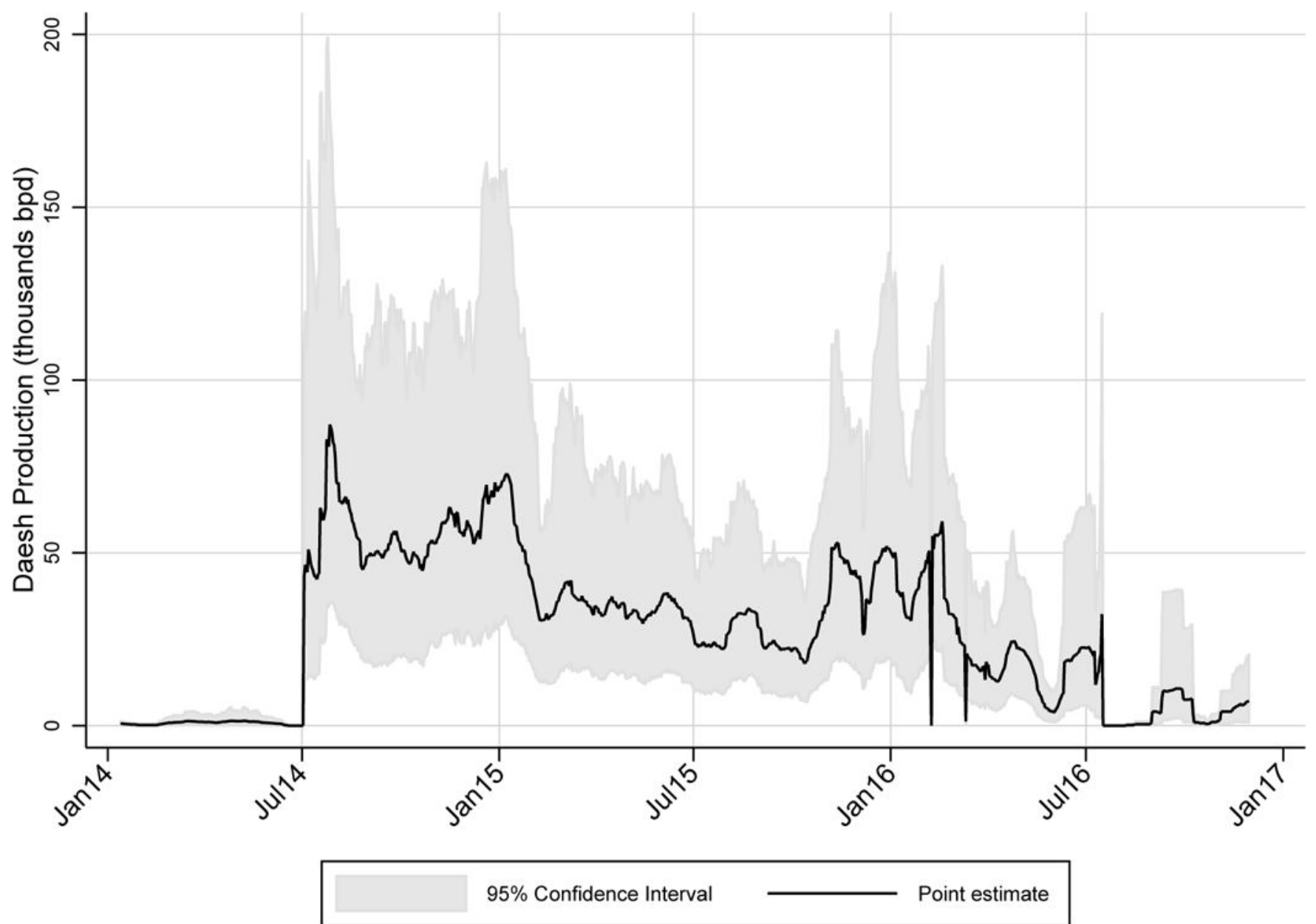

Fig. 3.

ISIL production estimates 2014-2016 assuming venting with 95\% confidence interval. 


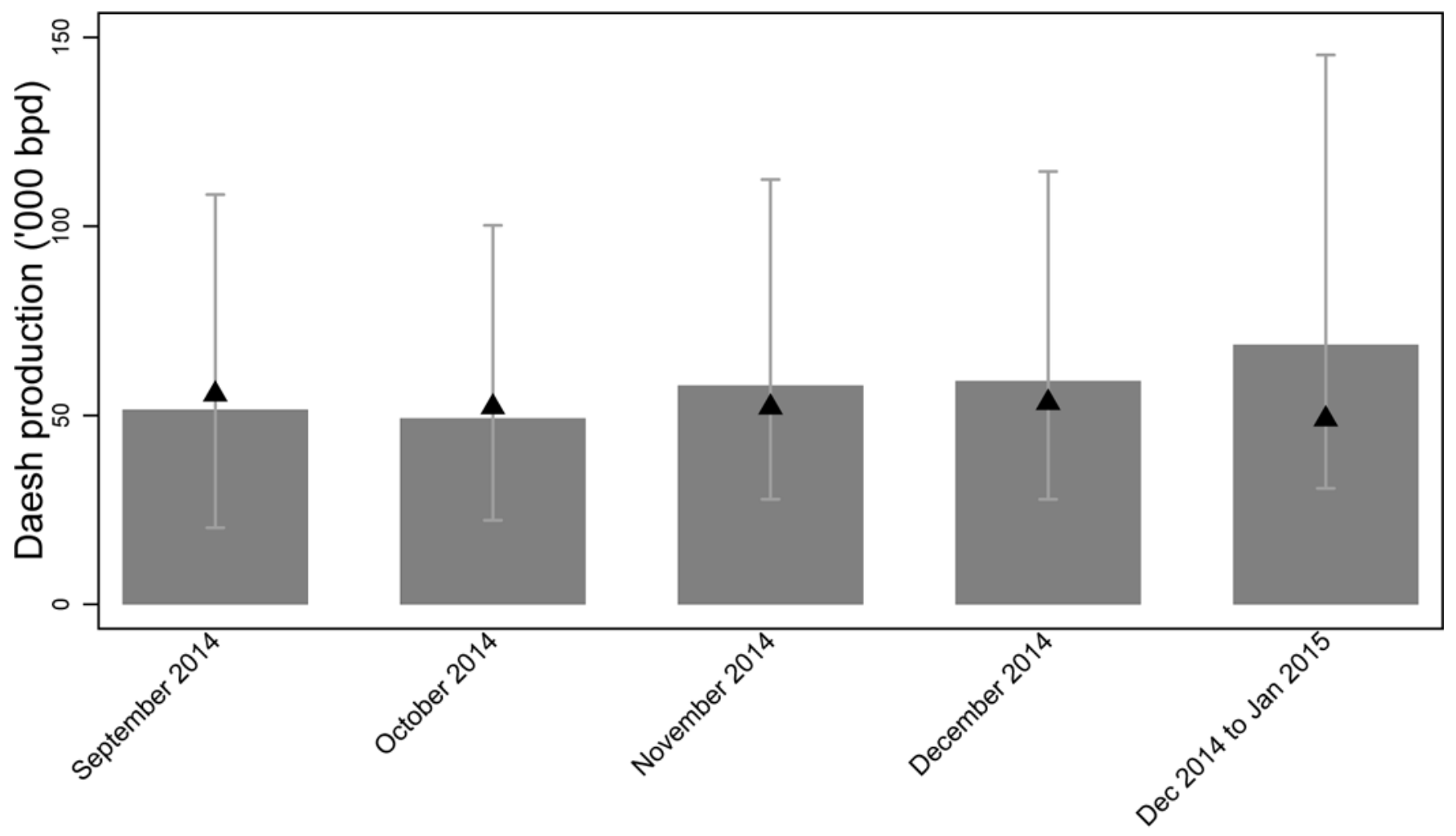

Daesh Reported Month

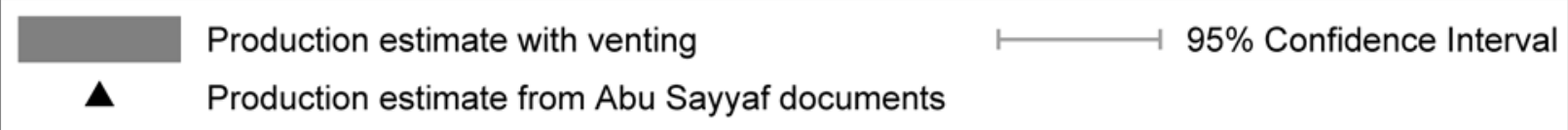

Fig. 4.

Estimate comparison to Abu Sayyaf reports. 
Extensive Productivity:
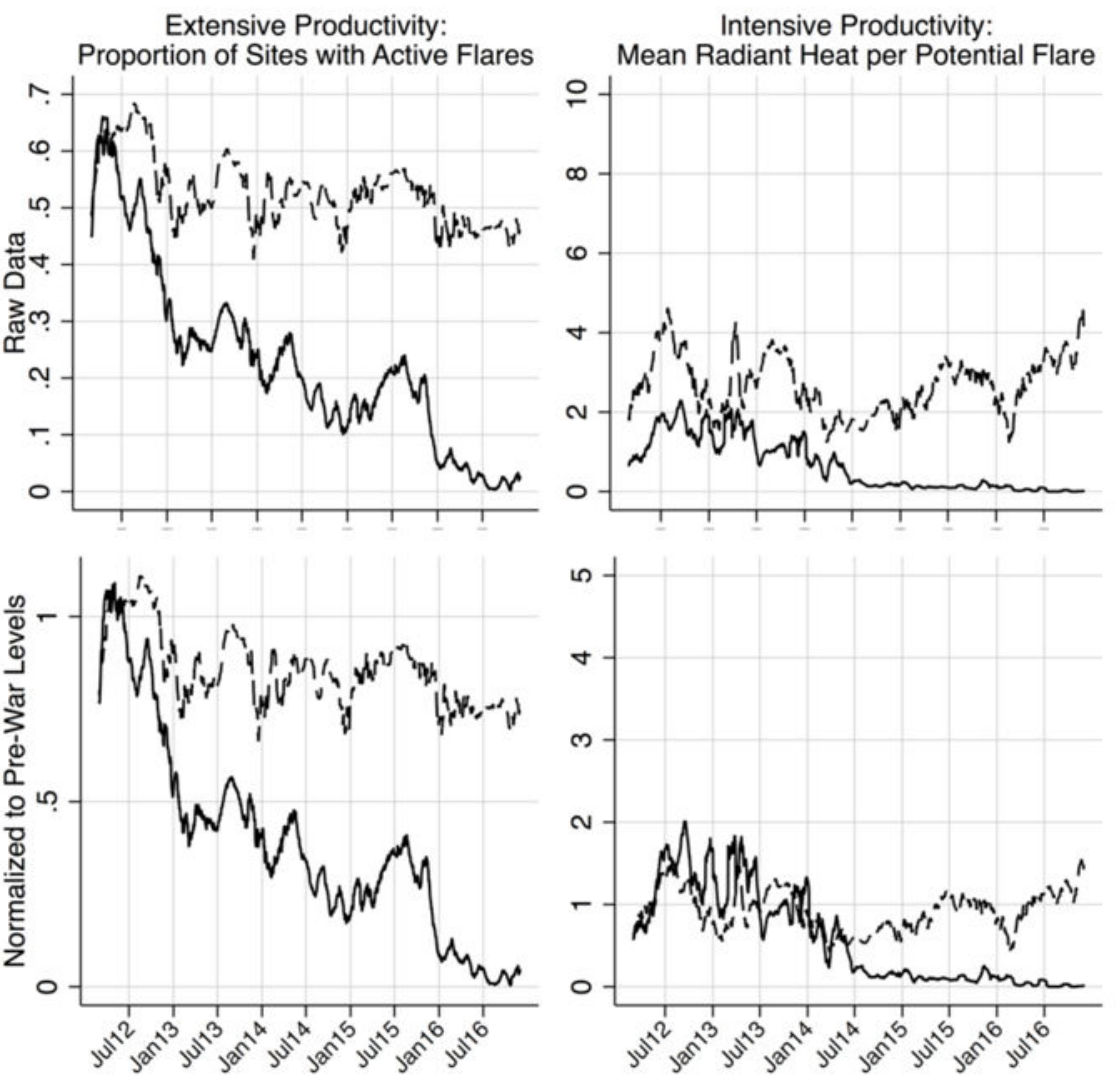
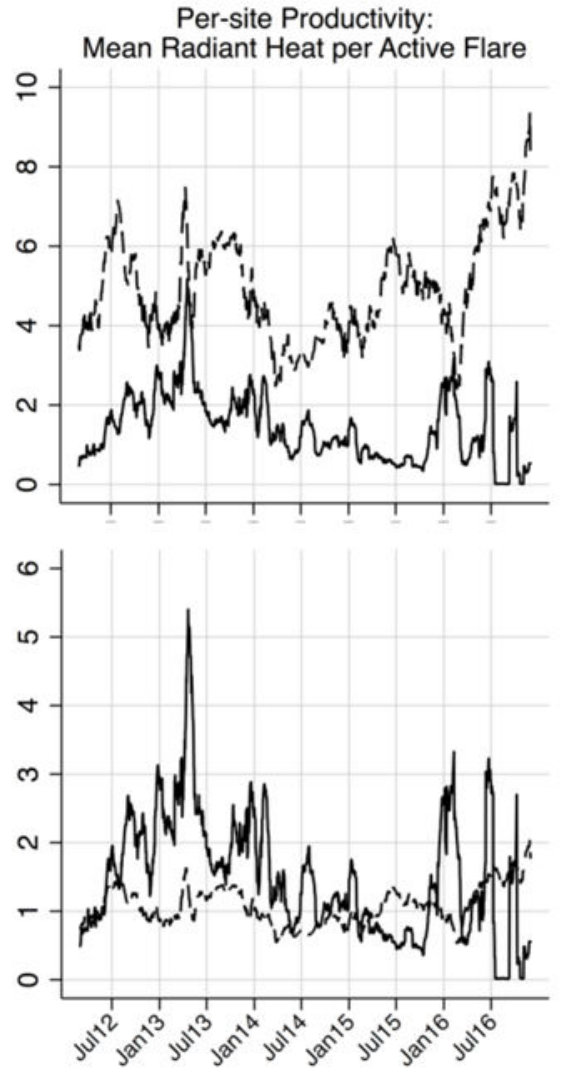

Fig. 5.

Output productivity: ISIL versus non-ISIL. 